\title{
THE DESIGN AND DEVELOPMENT OF TRANSITIONAL
}

\section{UAV CONFIGURATION}

\section{KARKERA YATHISH, SIDDALINGAPPA PK, SHELDON MASCARENHAS, CHINTHAN DSOUZA \& HITESH BALI}

Department of Aeronautical Engineering, Nitte Meenakshi Institute of Technology,

Yelahanka, Bangalore, Karnataka, India

\begin{abstract}
The transitional aircraft configuration is designed and developed, with a transitioning propulsion mounts from a hover mode to forward flight mode. Calculating the appropriate values of design parameters and performance characteristics was done initially keeping in mind, the take-off weight, usability and the payload carried by the aircraft. Complete modelling of the wing using Catia V5 and designing it for flow and structural analysis using ANSYS. The NACA 4415 airfoil with optimal dimensions is considered for the wing. The laser cutting technique is used in the fabrication. The fabricated model has been precision machined with the lightest materials to reduce weight and increase the efficiency. The autonomy is achieved with required configuration and coding using the KK2 board with manual PID tuning, thus gave full control at hand. The VTOL mechanism was built from scratch and is wirelessly controlled for flight operations.

KEYWORDS: Transitional Aircraft, Aircraft Design, UAV, VTOL \& RC Aircraft
\end{abstract}

Received: May 17, 2019; Accepted: Jun 10, 2019; Published: Jul 03, 2019; Paper Id.: IJMPERDAUG201953

\section{INTRODUCTION}

Transitional aircrafts are the hybrid unmanned aerial vehicles, which are able fly as fixed-wing aircraft as well as rotorcraft and transition between these modes. The development of transitional aircraft inspired by the operation of the helicopter, which makes the aircraft possible to take-off and land vertically, fly at low speeds and do some challenging manoeuvres. Many drawbacks of the fixed-wing enhanced the development of transitional aircrafts, since the wing stalls at low speed but some advantages over rotorcraft are also inspired due to the fact that, the better range, endurance, altitude, increased payload capacity can be achieved with high forward speed. We attempted to incorporate all these characteristics from both the configurations and we end up with the Transitional Aircraft (TA), which is a fixed wing, vertical Take-off and Landing (VTOL) with only two transitional tiltrotors, which is highly stable and which has high performance characteristics. Ashraf M Kamal [1] developed, the design methodology for hybrid unmanned aerial vehicles. Outcome of paper is, by using the proposed mathematical formulations; it is possible to develop a comprehensive design methodology for TA. This is executed by combining the performance characteristics of the helicopter, transition, and the fixed-wing aircrafts. The historical-data approach can be replaced by this design methodology, since it enables us to get many information used in the design of aircraft. The Small Vertical-Take-Off-Landing Unmanned Aerial Vehicle developed by Abd Rahman [2]. This hybrid VTOL UAV has the manoeuvring advantages such as the ability to travel fast, to perform transition flight safely with efficient propulsion system. The structural design parameters 
such as all-up-weight, wing design, fuselage design and tail design are calculated. The hybrid VTOL UAV prototype achieved its predicted flight performance with acceptable vibration levels in all axes. The study by John Rajadas [3] helped us to know the design, development, analysis, fabrication and testing of an Unmanned Aerial Vehicle (UAV). The propeller characteristics evaluated based on performance requirements and projected estimations of the loads acting on the UAV airframe lifts of up to $400 \mathrm{~N}$ measured at relatively low speeds ( $70 \mathrm{kmph})$. The performance study sufficient to fly the projected $28 \mathrm{~kg}$ aircraft at speed of 95-110 kmph in fixed wing mode. Sefer Kurnaz [4] developed the fuzzy logic modules under the main navigation and autonomous landing control system to control the global position of the air vehicle. A Standard Instrument Departure and Tactical Air Navigation approach are used to estimate performance characteristics of the fuzzy-based controllers using MATLAB. A survey on Autopilots for Small Fixed-Wing UAVs was done By Haiyang Chao [5]. This survey focussed on the use of control systems through GPS and inertial navigation systems through transmitter and receiver and the application of thermal and image sensing. They observed that many commercial autopilot systems are using traditional PID controllers since these are easy to understand and implement on the small UAV but in PID controller, it is difficult to tune the parameters since its limited robustness. They conclude that a good autopilot should be small, light with long endurance life, cost reduced and efficient. A fixed wing UAV was developed by Gesang Nugroho [6] to monitor disaster area, collecting real-time video and photos, equipped with image processing software. This UAV used a flying wing configuration that has $3 \mathrm{~kg}$ empty weight, $2.2 \mathrm{~m}$ wingspan, and has endurance of 12-15 minutes. Based on the study made on different papers on fixed wing VTOL aircraft and multi rotor UAV's, it is found that the fixed wing aircraft is better in terms of endurance and multirotor UAV's are better in terms of manoeuvrability. Combination of these two will give a Hybrid Aircraft can be called as Transitional Aircraft.

\section{METHODOLOGY}

\section{Detailed Design}

The final design is inspired by V-22 osprey [7], where we have used tilt rotor mechanism attached to the main spar of the main wing. This model is aerodynamically designed to achieve high endurance. The cambered aerofoil NACA 4415 is distinctly the most efficient aerodynamic shape since it produces higher lift coefficient than symmetrical aerofoil NACA 0015 [8]. A large negative pressure observed on the NACA 4415 at higher angle of attack, which increases the lift and this allows us to reduce the stall speed of the aircraft. The wing design calculations started with the pre-set constraints of maximum wingspan of $1 \mathrm{~m}$ and total weight of the aircraft of $18 \mathrm{~kg}$, ensuring good performance characteristics. It is achieved by studying the materials used in the aircraft and by considering all the electronics components. The design calculations have been done based on literature survey [2] and obtained specifications are shown in table 1. 
Table 1: The Transitional Aircraft Specifications

\begin{tabular}{|l|l|}
\hline \multicolumn{2}{|c|}{ Wing Specifications } \\
\hline Wing span & $1 \mathrm{~m}$ \\
\hline Wing chord & $0.1667 \mathrm{~m}$ \\
\hline Wing aspect ratio & 6 \\
\hline Wing area & $0.1667 \mathrm{~m}^{2}$ \\
\hline Taper ratio & 1 \\
\hline Disc loading & $5.2 \mathrm{~kg} / \mathrm{m}^{2}$ (on two rotors) \\
\hline Aileron area & $20 \%$ of wing area $=0.0576 \mathrm{~m}^{2}$ \\
\hline \multicolumn{2}{|c|}{ Euselage Specifications } \\
\hline Fuselage length & $70 \%$ of wing span $=0.7 \mathrm{~m}$ \\
\hline Fuselage cross section & Square type $\left(0.06 \times 0.06 \mathrm{~m}^{2}\right)$ \\
\hline \multicolumn{2}{|c|}{ Empena Specifications } \\
\hline Horizontal tail area & $20 \%$ of wing area \\
\hline Horizontal tail aspect ratio & 4.75 \\
\hline Horizontal tail taper ratio & 0.4 \\
\hline Elevator area & $25 \%$ of Horizontal tail $=8.334 \mathrm{e}^{-5} \mathrm{~m}^{2}$ \\
\hline Vertical tail area & $10 \%$ of wing area \\
\hline Vertical tail aspect ratio & 1.5 \\
\hline Vertical tail taper ratio & 0.4 \\
\hline Rudder area & $25 \%$ of Vertical tail $=4.167 \mathrm{e}^{-5} \mathrm{~m}^{2}$ \\
\hline
\end{tabular}

The NACA 4415 airfoil coordinates for the chord of $0.1667 \mathrm{~m}$ obtained from ref [9]. Catia V5 tool is used for modelling the wing based on the design calculations. The designed wing is comprise of I beam type cross-sectional relation in between stringers and spars. This is because I shaped arrangement allows a modular access and approach to construction of the wing. It also provides a greater efficiency in load transfer and resistance too bending moments acting on the wing. Therefore, keeping on mind, the presence of all these components, the 2D sketch was prepared with the right number of slots, and crevices. The location of these slots was determined keeping in mind the aerodynamic centre and the effects of moment generation about the aerodynamic centre. The camber of the airfoil at the outboard section is reduced and thus increase the stall angle at the tail of the wing. This allows the stall to take place first at the root of the wing and thus progress towards the tail. In addition, this increases the effective performance of the aileron and reduces the spinning effect of the tail. The method of generative shape design and surfacing was used to generate the 3D wing model, and later converted into a solid body using the 3D surface to solid conversion was used in the body set as shown in figure 1 . All the constituent parts joined and turned into one single body.

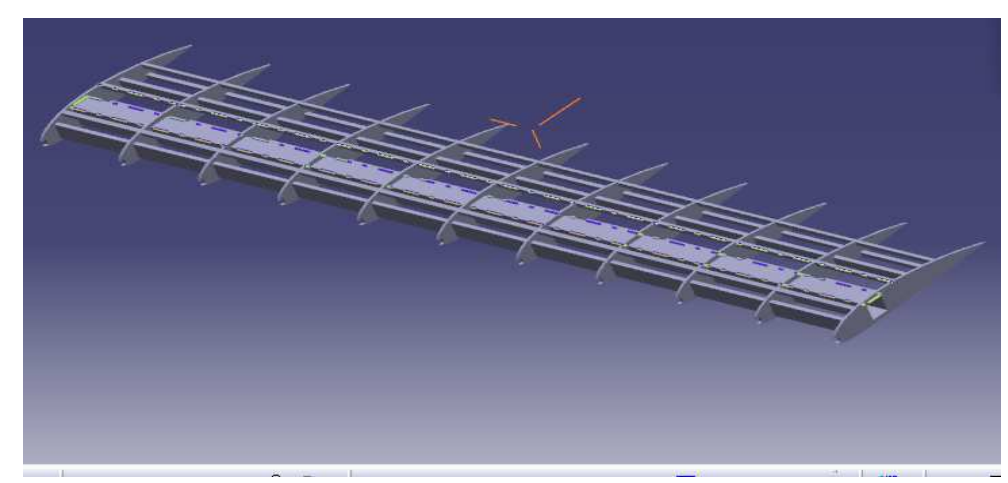

Figure 1: Representation of 3D Wing Modelled in CATIA V5 


\section{Fabrication}

Selecting the suitable fabrication method and material plays a very important role in aeromodelling. Depron was chosen for the construction of the fuselage and empennage because of its low cost and its flexibility. Balsa wood is selected to construct the wing, as it is lightweight and easy to sand characteristics. The monocoat is used as skin material, which is commercially available lightweight plastic shrink-wrap film. Aluminium rod is used as the main spar instead of balsa so that the tilt rotor mechanism can be fixed to it [10]. The fabricated transitional UAV based on the design is as show in figure 2 .

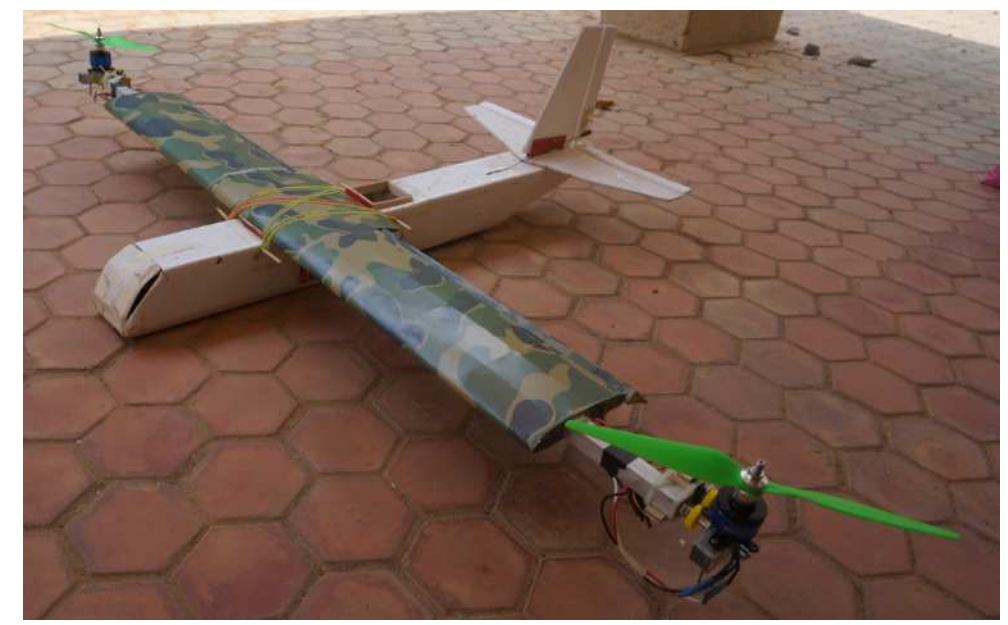

Figure 2: Fabricated Transitional UAV Based on the Design

\section{Propulsion System}

The propeller have been chosen based on the static thrust required to achieve stable hover state. The fixed pitch model aircraft propellers are used due to the reduction in both mechanical and control system design and the low inertia associated when we compare with variable-pitch propellers. Nylon, APC propeller were chosen as the most desirable propeller materials as they are highly durable, rigid and reasonably inexpensive, though less efficient than carbon fibre propellers [11]. The propeller size was estimated, based on the required static thrust and induced power of the electric motor using eCalc [12]. The final propeller consisted of 11" $\times 5.5 "$ APC glass-filled nylon two-blade-fixed-pitch propeller, which is available as a pusher pair. Brushless motors were chosen over the brushed motors to drive the propellers based on their high RPM and torque capabilities with the minimal associated wear. Electronic speed controllers (ESC) are used to give continuous $80 \mathrm{~A}$ current and Burst 100A up to 10 seconds with low voltage cut-off protection, over-heat protection and throttle signal loss protection. Lithium Polymer battery is selected, because of its higher gravimetric energy density. 5300mAh, 11.1v 50C Battery pack was chosen to power the propulsion unit. This Battery also increases the flight time. This weighed $400 \mathrm{gm}$ for the main motors.

\section{Aircraft Stability \& Control}

The aircraft Pitch is controlled by the gyroscope pitch stabilization with KK board. In hover, aircraft pitch is highly coupled with forward translation. Thus if the aircraft pitches down it will move forward as well due to the thrust being slightly non-vertical. The two separate motors at the wing tips used to create the differential thrust simply by differential motor speeds, which makes aircraft to roll. The yaw is controlled by differential longitudinal cyclic pitch, by using counter rotating motors, which are designed to rotate slightly more than 90 degree. The Auto stabilization is 
achieved by the use of gyroscope in the KK board, which can handle moderate gust loads.

\section{The Tilt Rotor Mechanism}

In a tilt rotor mechanism, we have used a hollow spar in order to reduce the wing weight with dimension $18 \times 18$ centimetres and an internal dimension of $16 \times 16$ centimetres. The hollow spar is attached to metal gear servo. The metal gear servo is used which can take the load upto $2 \mathrm{~kg}$. For the actuation of the control surfaces, plastic gear servos are used. Inside the hollow shaft, two bearings are placed, which allow the motion only in one direction and restrain the motion along other directions by the virtue of introducing a frictional component. In this case, the motion does not take place along a linear axis but does take place around a rotational axis. In order to reduce the torque acting on the given tilt rotor mechanism, we have used the gearing system consisting of two equal ratio toothed gears. One gear is attached to the shaft coming outside the spar and the other gear has been attached to the metal servo. The developed tilt rotor mechanism is as shown in figure 3.

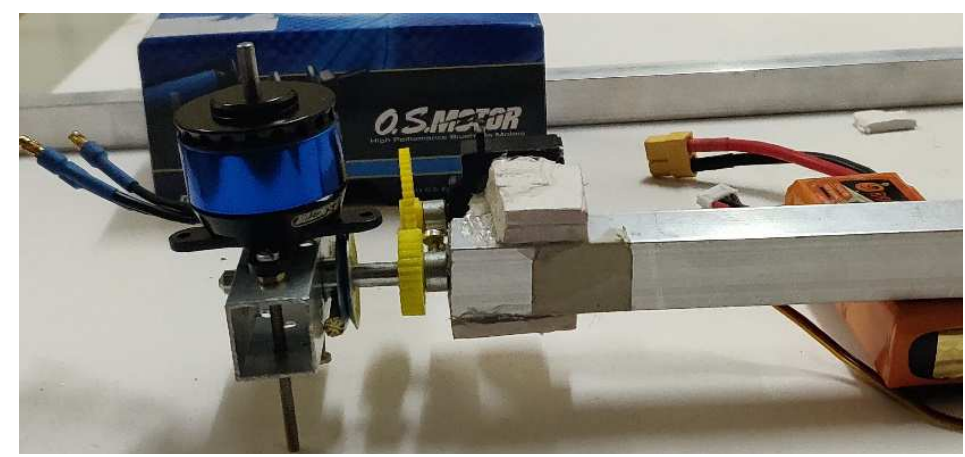

Figure 3: The Developed Tilt Rotor Mechanism

\section{Avionics}

Avionic RCB OS10 transmitter with $2.4 \mathrm{GHz}$ FHSS technology and 10 Channel facility is selected which provides a highly secure connection with RZ10 10 channel long-range receiver. KK2 board with manually controlled PID tuning, controls the stability and improvises/acts on the commands transmitted to it by the pilot. Incredibly sensitive KK2 board, 6050 MPU system with Atmel Mega644PA 8-bit AVR RISC-based microcontroller with 64k of memory is used. The used Receiver and KK2 board are as shown in figure 4.

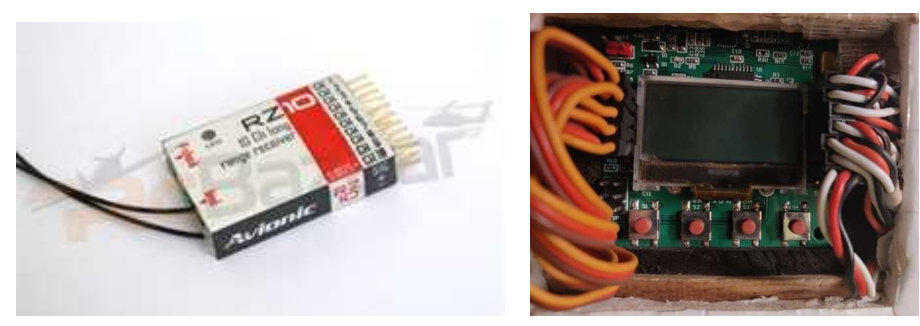

Figure 4: Receiver and KK2 Board

\section{CONCLUSIONS}

The transitional aircraft is designed and developed with twin rotor with greater endurance and thrust than any quad copter or a hex copter. The aircraft has achieved the vertical take-off and forward flight capabilities with help of twin tilt rotor mechanisms attached to the main wing. Structural and load bearing capacity has been achieved as a result the mechanism is capable of resisting unwanted torque. This transitional aircraft utilizes the KK2 board, which takes into 
account the most manually controlled PID tuning thus providing greater configurational capacity than other flight controllers. The wing so designed has used structural components such as spars and ribs made from balsa wood and covered with a layer of monocoat, this helps give a huge reduced wing weight and really smooth surface for the airflow. The flow analysis using the ANSYS 16 was carried out which helped in selection of airfoil.

\section{FUTURE SCOPE}

In future, this transitional aircraft can be modified to take up payloads of greater weights in order to provide logistical services to average consumers, as the logistical transport by UAVs is the one of the most trending and growing sectors in aeronautics.

\section{REFERENCES}

1. Kamal AM, Ramirez-Serrano A (2018). Design methodology for hybrid (VTOL + Fixed Wing) unmanned aerial vehicles. Aeron Aero Open Access J. 2018;2(3):165-176. DOI: 10.15406/aaoaj.2018.02.00047

2. Abd Rahman, Y. A., Hajibeigy, M. T., Al-Obaidi, A. S. M., \& Cheah, K. H. (2018). Design and Fabrication of Small VerticalTake-Off-Landing Unmanned Aerial Vehicle. MATEC Web of Conferences, 152, [02023].

https://doi.org/10.1051/matecconf/201815202023

3. Rajadas, J., \& Post, A. (2007). Design, fabrication and testing of a novel UAV: Capstone project. ASEE Annual Conference and Exposition, Conference Proceedings.

4. Kurnaz, Sefer \& Cetin, Omer (2010). Autonomous Navigation and Landing Tasks for Fixed Wing Small Unmanned Aerial Vehicles. Acta Polytechnica Hungarica. Vol. 7, No. 1,

5. H. Chao, Y. Cao and Y. Chen (2010). "Autopilots for Small Fixed-Wing Unmanned Air Vehicles: A Survey," 2007 International Conference on Mechatronics and Automation, Harbin, pp. 3144-3149. DOI: 10.1109/ICMA.2007.4304064

6. Nugroho, Gesang \& Taha, Zahari \& Setya Nugraha, Tedy \& Hadsanggeni, Hatyo. (2015). Development of a Fixed Wing Unmanned Aerial Vehicle (UAV) for Disaster Area Monitoring and Mapping. Journal of Mechatronics, Electrical Power, and Vehicular Technology. 6. 83. 10.14203/j.mev.2015.v6.83-88.

7. V-22 Osprey - Military Aircraft, https://fas.org/man/dod-101/sys/ac/v-22.htm

8. Rubel, Robiul. (2017). Comparison of aerodynamics characteristics of NACA 0015 \& NACA 4415 aerofoil blade. 5. 187-197. 10.5281/zenodo.1095406.

9. NACA 4 digit airfoil generator (NACA 4415 AIRFOIL) - Airfoil Tools. http://airfoiltools.com/airfoil/details?airfoil=naca4415-il

10. Raymer, D, P (1999). Aircraft Design: A Conceptual Approach (Reston: AIAA Education Series)

11. M. F. Saharudin, (2017). "Development of tilt-rotor unmanned aerial vehicle (UAV ): material selection and structural analysis on wing design," in IOP Conference Series: Materials Science and Engineering

12. Sivakumar, S., Ranjithkumar, N., \& Ragunathan, S. (2013). Design and development of down draft wood gasifier. International Journal of Mechanical Engineering, 2(2), 1-10.

13. The most reliable RC Calculator on the Web. https://www.ecalc.ch/ 